\title{
PERANCANGAN AUGMENTED REALITY BERBASIS ANDROID SEBAGAI PROMOSI TAMAN SRIWEDARI SURAKARTA
}

\author{
N ur H anifati Widayaningsih ${ }^{1}, \mathrm{H}$ andriyotopo ${ }^{2}$ \\ 1Program Studi (S1) Desain Komunikasi Visual \\ Fakultas Seni Rupa dan Desain, Institut Seni Indonesia Surakarta \\ Email: nurhanifati@gmail.com \\ 2Institut Seni Indonesia (ISI) Surakarta \\ Email: handriyotopo@gmail.com
}

\begin{abstract}
A bstract
Taman Sriwedari Surakarta is a cultural heritage treasure that needs efforts to preserve and introduce historical buildings and cultural values to the public, especially young people, through Android-based augmented reality technology. The purpose of this design is that the public can enjoy historical videos, exterior buildings, and the revitalization of the 2018 Surakarta Sriwedari Park video based on android. The design of A ugmented Reality becomes more attractive, interesting, and educational as well as a means of preserving Surakarta Sriwedari Park as a cultural heritage. This design uses the diffusion analysis of innovation, the M ultimedia D evelopment Live Cycle method, layout design, selection of typography and colors that have aesthetic values. The results of this design are in the form of identity creation, a catalog book containing markers and information, and an application called SriwedA Ri. An advertising promotion strategy in an effort to introduce this product uses above and below the line media as well as through online stores.
\end{abstract}

Keyword: Taman Sriwedari Surakarta, A ugmented R eality, diffusion of innovation, marker.

\begin{abstract}
A bstrak
Taman Sriwedari Surakarta merupakan harta artefak warisan budaya yang perlu dilakukan upaya untuk melestarikan serta mengenalkan bangunan sejarah dan nilai budaya kepada khalayak khususnya anak muda melalui teknologiAugmented Reality berbasis android. Tujuan dari perancangan ini yaitu agar masyarakat dapat menikmati video sejarah, bangunan eksterior, dan video revitalisasi Taman Sriwedari Surakarta tahun 2018 berbasis android. Perancangan Augmented Reality menjadi lebih atraktif, menarik, dan mendidik serta sebagai sarana pelestarian Taman Sriwedari Surakarta sebagai cagar budaya. Perancangan ini menggunakan analisis difusi inovasi, metode M ultimedia D evelopment LiveCycle, layout design, pemilihan tipografi dan warna yang memiliki nilai estetik. Hasil dari perancangan ini berupa pembuatan identitas, buku katalog yang berisikan marker dan informasi, serta aplikasi bernama SriwedA Ri. Strategi promosi periklanan sebagai upaya memperkenalkan produk ini menggunakan media above and below the line juga melalui toko online.
\end{abstract}

Kata Kunci: Taman Sriwedari Surakarta, A ugmented Reality, difusi inovasi, marker.

\section{PENG ANTAR}

Warisan budaya sebagai harta pusaka budaya baik berwujud atau tidak berwujud. Bersumber dari masa lampau untuk kehidupan masyarakat sekarang dan kemudian diwariskan kembali untuk generasi yang akan datang secara berkesinambungan. Warisan budaya masa lalu yang diwariskan dari generasi yang satu kepada generasi yang lain, yang 
tetap dilestarikan, dilindungi, dihargai, dan dijagakepemilikannya (A rdika, 2007: 19).Seperti halnya Indonesia memiliki warisan sejarah budaya baik fisik dan non fisik.

A ugmented reality adalah salah satu teknologi yang menjadi isu dan tren teknologi masa kini (Pascasarjana Universtas N egeri Malang, 2016: 27-28). Teknologi A ugmented R eality memiliki potensi yang besar baik sebagai sarana edukasi maupun entertainment. Salah satu keuntungan yang dapat diperoleh dari aplikasi A ugmented R eality untuk tujuan edukasi yaitu meningkatkan pemahaman objek yang sedang dipelajari, dan berdasarkan data IDC (International Data Corporation) pada tahun 2016 Android memegang 86,8\% market share smartphone di seluruh dunia, sehingga pemilihan android sangat tepat sasaran khusunya pengguna saat ini telah banyak menggunakannya.

Melihat kondisi dari Taman Sriwedari Surakarta dalam sejarahnya dahulu kala merupakan fenomena wisata budaya di Kota Surakarta, karena kualitas karakteristik budaya yang dimiliki dan juga nilai historisyang tidak lepas dari masyarakat. Taman ini juga menjadi bagian sejarah baik bagi kota Surakarta maupun bagi Negara. Dunia baru yang menyisakan jarak bagi dunia lama, membuat hawa intelektual di taman ini berangsur pupus, wajah rekreasi edukatif pada taman ini nampak memucat dan keceriaan warnanya terus memudar hingga hari ini.

Teknologi canggih yang ditawarkan sebagai solusi langkah untuk mewujudkan promosi dalamPerancangan Augmented Reality Berbasis ANndroid Sebagai Promosi Taman Sriwedari Surakartayaitu A ugmented Reality merupakan suatu teknik untuk menggabungkan object dari dunia maya ke dunia nyata dengan kamera smartphoneandroiddiperlukan untuk menangkap gambar marker. M arker yang dimaksud di sini adalah pola yang dibuat, dalam bentuk gambar yang akan dikenali oleh kamera, sehingga dapat ditampilkan informasinya berupa gambar 3D bangunan eksterior, serta pembuatan aplikasi dan buku katalog yang nantinya berisikan informasi mengenai video sejarah dari taman ini, 3D bangunan eksterior Pendopo Joglo, Gedung Wayang Orang, Museum Radya Pustaka, Museum Keris, Gedung Kesenian Solo, Taman Hiburan Rakyat Sriwedari, dan video trackview hasil dari revitalisasi pada tahun 2018, dalam mempromosikan Taman Sriwedari Surakarta dengan menggunakan teknologi agar lebih interaktif.

Metode penciptaan merupakan proses dalam merealisasikan gagasan atau ide ke dalam sebuah karya. Hal ini merupakan pijakan sebagai dasar dalam pembuatan karya. Metode yang digunakan dalam proses Perancangan Augmented Realityberbasis android 
eISSN 2774-2792

p-ISSN 2774-2806

Vol. 1 No. 2, Desember 2020

sebagai promosi Taman Sriwedari Surakarta dengan teknologi Augmented Realityyang menggabungkan interaksi alami, nyata dan kaya akanrealitas fisik denganbebas dari kendala dan presisi digital di dunia. Salah satu manfaat aplikasi ini menjadibagian dari realitas fisik user atau pengguna adalah berpotensi dapat tampil lebih intuitif danmenyediakan antarmuka yang user-friendly untuk orang non-teknis, terdiri dari pengumpulan data, analisis data menggunakan analisis difusi inovasi, dan metode perwujutan.

Metode pengumpulan data dalam perancangan A ugmented Realityberbasis android sebagai promosi Taman Sriwedari Surakarta menekankan pada pembuatan buku katalog, aplikasi, dan media promosi kepada masyarakat luas khususnya anak muda, menggunakan data bangunan bersejarah pada area taman tersebut sebagai masukan awal dalam penciptaan model tiga dimensi.Data diperoleh denganwawancara dengan Ibu Sruti Respati dari dinas periwisata dan kebudayaan Kota Surakarta, bertugas pada bagian staff sub dinas sarana wisata, studi pustaka melalui beberapa buku di antaranya Multimedia Interaktif Dengan Flash ( A riesto Hadi Sutopo ), A ugmented Reality for Android A pplication Development ( Jens Grubert, Dr. Raphael Grasset ), Augmented Reality For Geginners!( Rozer Froze ), Pro A ndroid A ugmented R eality (Raghav Sood ), M ultimedia D evel opment Lifecycle (Swiss German University Indonesia). Observasi ke lokasi Taman Sriwedari Surakarta menggunakan teknik fotografi dan mencari data di internet.

Metode analisis data dalam perancangan A ugmented Real ityberbasis android sebagai promosi Taman Sriwedari Surakarta yaitu menggunakan analisis difusi inovasi dipengaruhi 4 elemen pokok yang nantinya akan berdampak pada perkembangan teknologi, terdiri dari Inovasi, yaitu sebuah ide baru dalam penyampaian sebuah informasi atau interaksi. Saluran komunikasi, adalah suatu pesan yang disampaikan dalam bentuk khusus.Dalam hal ini A ugmented R eality.W aktu, cepat atau lambatnya penerapan atau adopsi teknologi bergantung pada penerimaan masyarakat tentang ide baru dalam teknologi.Sistem sosial, perubahan yang terjadi baik perubahan minor atau major dalam pengaplikasian teknologi.

1. Inovasi

Inovasi adalah ideatau gagasan yang dianggap baru oleh seseorang. Teknologi A ugmented Reality masih dianggap baru oleh sebagian besar masyarakat khususnya masyarakat indonesia. Buku katalog Taman Sriwedari Surakarta in A ugmented Reality dan aplikasi SriwedARi memungkinkan pengguna smartphone mengatahui informasi tentang Taman Sriwedari Surakarta khususnya bangunan yang ada di dalamnya dalam bentuk 3D (tiga 
dimensi) kapan saja dan di mana saja tanpa harus mengunjungi Taman Sriwedari yang berlokasi di kota Surakarta. Keunggulan lainnya yaitu aplikasi tersebut tidak memerlukan akses atau koneksi internet.

2. Saluran Komunikasi

saluran komunikasi yang dapat digunakan, yaitu media massa dan interpersonal. Saluran komunikasi sebagai sarana untuk menyebarkan inovasi.teknologiA ugmented Reality memperkaya dunia nyata dengan konten virtual. Penggunaan aplikasi smartphone sebagai media pembelajaran atau sebagai media promosi dinilai lebih efektif dan menarik karena masyarakat selalu tertarik pada ide atau desain baru.

3. Waktu

Proses difusi membutuhkan jangka waktu yang cukup panjang karena ada beberapa hal yang harus dilalui. Tahapan dalam proses difusi inovasi buku katalog Taman Sriwedari Surakarta in A ugmented Realitydan aplikasi sriwedARi meliputiknowledge (tahap pengetahuan), proses dimana suatu inovasi dikomunikasikan kepada khalayak umum melalui media cetak, baik itu iklan di koran, majalah atau poster yang ditempatkan di lokasi umum.Persuasion (tahap persuasi)terjadi ketika individu memilih untuk bersikap positif atau negatif terhadap inovasi, dalam hal ini buku katalog Taman Sriwedari Surakarta in Augmented Reality dan aplikasi SriwedARi.D ecision (keputusan)akan membawa individu atau pengguna aplikasi menimbang keuntungan atau kerugian suatu inovasi. ketertarikan dan manfaat akan buku katalog Taman Sriwedari Surakarta in A ugmented Reality dan aplikasi SriwedARi akan diterima atau ditolak oleh pengguna dalam tahap ini.

\section{Sistem Sosial}

Buku katalog Taman Sriwedari Surakarta in A ugmented Reality dan aplikasi SriwedA Ri akan diproses kemudian diadopsi oleh pengguna (user) dan dapat diterapkan dalam sistem sosial yang berlaku.

Proses penciptaan karya A ugmented Reaity berbasis android sebagai promosi Taman Sriwedari Surakarta menggunakan metode pengembangan sistem yang digunakan dalam perancangan ini adalah model pengembangan versi Luther-Sutopo yang dikenal dengan metodeM ultimedia D evelopment Live Cycle (MDLC). M ultimedia D evelopment Live Cycle terdiri dari enam tahap, yaitu Concept, design, material collecting, assembly, testing dan distribution(Luther dalam Sutopo, 2012 :128). Keenam tahap ini harus berurutan, dalam praktiknya, tahap-tahap tersebut dapat saling bertukar posisi. 


\section{a. Concept}

Dalam tahap ini ada beberapa hal yang perlu diperhatikan, antara lain:

1) Menentukan tujuan perancangan Augmented Reality sebagai promosi Taman Sriwedari Surakarta yaitu terciptanya sebuah aplikasi media promosi Taman Sriwedari Surakarta yang dapat memberikan pengetahuan dan gambaran tentang taman tersebut, menggunakan teknologi Augmented Reality sehingga tampak secara realtimeberbentuk eksterior 3 dimensi dan video berupa sejarah taman tersebut agar lebih interaktif serta ada juga tambahan video track view dari proyek revitalisasi tahun 2018 pada taman tersebut.

2) PerancanganAugmented RealityBerbasis Android sebagai promosi Taman Sriwedari ini berjalan dan dioperasikan pada perangkat operasi smartphone android.

\section{b. Material collecting}

Pada tahap ini, materi terkait didapatkan dari wawancara, studi pustaka, observasi dengan cara terjun langsung ke lokasi, dan mencari data di internet.

\section{c. Design}

Pada tahapdesign perancangan Augmented Reality sebagai promosi Taman Sriwedari Surakarta yaitu Perancangan Augmented Reality secara mobile, dalam perancangan ini menggunakan platform android yang nantinya akan diuji coba di beberapa device untuk mengetahui tingkat kelancaran, bug dan beberapa faktor lainnya.

1) Alat dan bahanPerancangan ini memerlukan peralatan utama dan pendukung untuk perancangan dan mengimplementasikan aplikasi, peralatan yang digunakan dengan kriteria $\mathrm{H}$ ardware terdiri dari Seperangkat komputer dan Beberapa unit smartphone dengan OS A ndroid berbagai merk dan Software menggunakan U nity 3D, Sketchup, A ndroid SD K dan Cry Engine

2) Perancangan desain eksterior untuk bentuk 3 dimensibeberapa bangunan yang ada di Taman Sriwedari Surakarta dengan hasil format export file kedalam bentuk 3ds

3) Pembuatan video animasi kinetic typography mengenai sejarah Taman Sriwedari Surakarta.

4) Pembuatan video track view proyek revitalisasi Taman Sriwedari Surakarta tahun 2018.

5) Membuat desain marker media promosi berupa buku katalog yang nantinya akan digabungkan dengan Augmented Reality. Hasil desain marker ini akan dicetak berupa buku untuk memastikan dimensi marker yang tepat. Prinsip kerja marker ini yaitu ketika sebuah aplikasi Augmented Reality menemukan kecocokan dengan hasil identifikasi marker, baik melalui pelacakan marker-based maupun markerless. Dengan demikian, 
aplikasi dapat melakukan aksi tertentu, jika aplikasi mengenali sebuah marker tertentu, maka aplikasi tersebut akan menampilkan informasi berlapis (overlay) di atas citra marker yang diidentifikasi. berupa gambar 3 dimensi.

6) Perancangan desain user interface agar nantinya aplikasi tersebut dapat menarik dan memiliki ciri khas tersendiri.

\section{d. Assembly}

Tahap assembly(pembuatan) yaitu Penggabungan gambar markerdari bangunan eksterior Pendopo Joglo, Gedung Wayang Orang, Museum Radya Pustaka, Museum Keris, Gedung Kesenian Solo, Taman Hiburat Rakyat Sriwedari, video sejarah Taman Sriwedari Surakarta, dan video track view revitaliasasi pada tahun 2018, akan dikombinasikandengan A ugmented Reality, semua objek atau material tersebut dibuat dan digabungkan menjadi satu aplikasi yang utuh, dalam tahapan ini digunakan beberapa software seperti U nity 3D, Blender, Sketchup dan Cry Engine.

\section{e. Testing}

Tahap ini disebut juga sebagai tahap pengujian alpha (alpha test) aplikasi Augmented Reality sebagai media promosi Taman Sriwedari Surakarta di mana pengujian dilakukan di beberapa devicesmartphone android yang berbeda merk untuk mengetahui tingkat kelancaran, bug, dan beberapa faktor lainnya.

\section{f. Distribution}

Dalam tahapan ini, aplikasi yang telah selesai di uji dan dinyatakan baik sesuai dengan tujuan pembuatan, akan didistribusikandalam rangkapromosi berupa buku katalog dan aplikasi menggunakan media lini atas menggunakan media berupa billboard dan surat kabar. Media lini bawah menggunkan berupa pembatas buku, stiker, gantungan kunci dan pin, untuk media cetaknya menggunakan iklan pada poster dan x stand banner.Iklan pada media sosial pada akun instagram dan facebook. Hasil aplikasi akan di uploud di playstore, untuk mempermudah calon konsumen mendapatkanproduk ini akan tersedia pada toko online Shopee, Buka Lapak dan Tokopedia, berikut ini hasil gambar dari diagram alir "Perancangan A ugmented Reality Berbasis A ndroid Sebagai Promosi Taman Sriwedari Surakarta": 


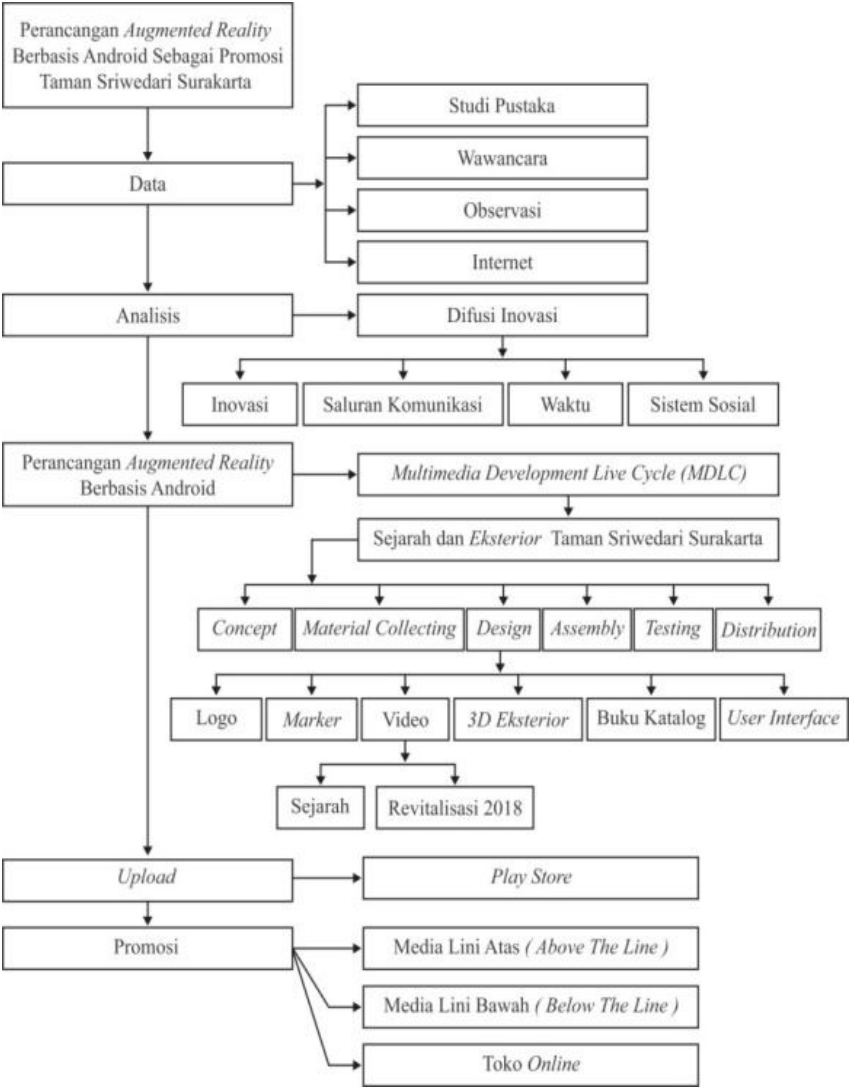

Gambar 1 Diagram Alir Perancangan Karya (Dok. Nur Hanifati Widyaningsih 2018)

\section{PEM BAHASAN}

\section{Konsep KreatifA ugemted RealityTaman Sriwedari Surakarta}

Konsep kreatif yang diinginkan yaitu membuat sebuah A ugmented Realty berbasis android sebagai promosi Taman Sriwedari Surakarta, berupa buku katalog yang dapat dilihat menggunakan smartphone android dengan menginstal aplikasi SriwedARi. Buku Katalog interaktif ini akan memberikan sebuah informasi secara realtime dari penggabungan dunia maya dengan dunia nyata, menyuguhkan informasi mengenai video sejarah, 3D bangunan dari taman tersebut, dan video track view dari revitalisasi Taman Sriwedari Surakarta tahun 2018. Strategi komunikasi yang terdapat dalam perancangan ini yaitu sebagai berikut. 
a. Fakta Kunci

1) Taman Sriwedari merupakan cagar budaya berupa taman tertua di Kota Surakarta serta mengandung sejarah yang perlu dijaga sebagai warisan budaya.

2) Taman Sriwedari merupakan taman di Kota Surakarta memliki letak yang strategisdengan sebelah utara jalan Slamet Riyadi, sebelah timur terdapat museum, sebelah selatan yaitu jalan Kebangkitan Nasional dan sebelah timur merupakan kelurahan Laweyan Kota Surakarta.

3) Taman Sriwedari memiliki bangunan ekterior yang cukup unik serta mengandung sejarah.

\section{b. Masalah Yang Ingin Dikomunikasikan}

1) Memberikan informasi mengenai sejarah, bangunan eksterior, danproyek revitalisasi dari Taman Sriwedari Surakarta pada tahun 2018

2) Menunjukan bahwa Taman Sriwedari Surakarta merupakan suatu warisan cagar budaya yang perlu dicintai sebagai barang berharga berupa warisan sejarah dan layak dijadikan tempatwisata lokal maupun non lokal Kota Surakarta.

\section{Tujuan Yang Dicapai}

1) Merancang aplikasi A ugmented Reality berbasis Android untuk media promosi Taman Sriwedari Surakarta.

2) Membuat media promosi untuk buku katalog Taman Sriwedari Surakarta inA ugmented Reality dan aplikasi SriwedARi agar dapat mengajak masyarakat secara luas khusunya anak muda untuk memakai produk ini dan menanamkan rasa cinta untuk peduli terhadap peninggalan sejarah berupa cagar budaya yaitu Taman Sriwedari Surakarta.

\section{d. Profil Target Konsumen}

1) Demografis

Demografi atau kependudukan harus mencakup seluruh kalangan/golongan masyarakat dari berbagai lapisan. Faktor demografi yang digunakan paling luas adalah jenis kelamin, usia, besarnya keluarga, penghasilan, pekerjaan, pendidikan, agama, ras, kebangsaan dan kelas sosial. Peninjauan dilakukan terhadap khalayak sasaran yang akan diperuntukkan dalam perancangan ini. Demografi sasaran promosi ini yakni wisatawan lokal Kota Surakarta maupun wisatawan non lokal khususnya anak muda.

\section{2) Geografis}

Daerah menjadi sasaran promosi ini berada didalam maupun luar Kota Surakarta yang memiliki banyak wisatawan yang tidak hanya berkunjung saja menikmati panorama keindahan namun juga belajar akan sejarah suatu tempat tersebut. 


\section{3) Psikologi}

ketertarikan, opini, sikap, personalitas, dan gaya hidup dilihat dari segi psikografis calon penggunaAplikasi SriwedARi dan buku katalog ini adalah semua wisatawan lokal maupun non lokal Kota Surakarta

\section{4) Behaviora}

Media sarana pendukung promosi Aplikasi SriwedARi dan buku katalog Taman Sriwedari Surakarta in A ugmented Reality tersebut diharapkan dapat menarik perhatian sesuai dengan sasaran dan efektif dalam penyampaian pesan maupun informasinya, serta memiliki ciri khas desain agar mudah dikenali

\section{Strategi Kreatif VisualA ugmented Reality}

Tema perancangan dan gaya desain akan membantu perancangan strategi kreatif visual yang digunakan dalam perancangan A ugmented Reality berbasis android sebagai promosi Taman Sriwedari Surakarta. Strategi kreatif visual meliputi strategi visual verbal dan non verbal.

\section{a. Strategi Visual Verbal}

Penerapan strategi visual dalam perancangan media promosi A ugmented Reality bebasis android Taman Sriwedari Surakarta membutuhkan unsur-unsur naskah iklan yang terdiri dari judul (headline), teks (bodycopy), baseline, dan tagline.Adapun lebih jelasnya dijelaskan seperti berikut :

\section{1) Judul (Headline)}

Judul atau headline merupakan hal yang pertama kali dibaca dan diharapkan dapat memancing para audiens untuk membaca lebih lanjut mengenai isi teks (bodycopy) lebih lanjut secara detail. Kata-kata headl ine hendaknya singkat, informatif sehingga dalam penerapannya mudah dibaca dengan jelas. Biasanya penggunaan headline ditampilkan lebih besar dari pada material visual lainnya dalam sebuah perancangan media promosi melalui media komunikasi visual.H eadline yang dipakai dalam perancangan buku katalog Augmented Reality bebasis android Taman Sriwedari Surakarta yaitu "TAMAN SRIWEDARI SURAKARTA"

\section{2) Sub Judul (Sub Headline)}

Digunakan sebagai penguat dari sebuah Judul. Kalimat dalam sub headline lebih mudahdan menarik agar mudah dipahami oleh pembaca. sub headline yang akan 
digunakan pada buku katalogAugmented Reality berbasis android Taman Sriwedari Surakarta ini adalah "IN A U GM ENTED REA LITY". Hal tersebut disesuaikan dengan produk karya ini yaitu sebuah teknologi A ugmented Reality

\section{3) Teks (Body Copy)}

Memiliki peran sebagai penjelas yang bersifat inovatif dalam penyampaiannya. Pesan yang disampaikan bersifat ringkas, sederhana dan dapat mewakili segala seuatu terkait maksud dan tujuan headline dan sub headline yang sebelumnya sudah ditentukan. Teks (body copy) dalam perancangan ini, fokus pada berbagai informasi terkait segala hal mengenai Taman Sriwedari Surakarta khususnya eksterior dan sejarah dari taman ini. Hal tersebut, selain digunakan sebagai upaya agar wisatawan dapat tertarik untuk lebih mengenal dan mencintai cagar budaya warisan leluhur berupa tempat wisata budaya.

\section{4) Tagline}

Adalah kalimat yang merupakan inti dari nilai jual dan kualitas sebuah produk yang dikenalkan dan ditempatkan dalam benak konsumen.Dalam penciptaannya, tagline dilatar belakangi oleh pemikiran yang menawarkan salah satu keunggulan suatu produk.Tagline yang digunakan dalam perancangan untuk kepentingan promosi produk ini yaitu “Enjoy Real and V irtual in SameTime".

\section{Strategi Visual Non Verbal}

Dipergunakan untuk mengisi beberapa unsur pendukung dalam penerapan strategi visual verbal.Sehingga audiens tidak merasa jenuh dalam memahami segala sesuatu terkait media promosi yang digunakan. Adapun strategi visual non verbal yang terdiri dari :

\section{a) Ilustrasi}

Ilustrasi merupakan hasil visualisasi dari proses teknik sketsa gambar, lukisan, fotografi maupun teknik seni rupa lainnya. Tujuannya yaitu untuk melengkapi atau menghiasi suatu tulisan tertentu dengan harapan mudah dicerna oleh audiens. Ilustrasi yang digunakan dalam perancangan ini menitikberatkan pada teknik Augmented Reality, 3D (tiga dimensi) dan Video, dengan maksud dan tujuan agar audiens dapat melihat secara nyata produk ini memiliki keunggulan yang unik sebagai sarana untuk mempromosikan Taman Sriwedari Surakarta.

\section{b) Tipografi}

Tipografi merupakan seni memilih huruf diantara berbagai macam rancangan dan desain huruf yang tersedia. Desain huruf tertentu dapat menciptakan gaya dan karakteristik 
subjek yang diiklankan. Jenis huruf yang dipakai, adalah jenis huruf yang memiliki kesan kuat, tegas, terbuka, dan modern.Jenis huruf yang dipakai dalam perancangan promosi aplikasi dan katalog Sriwedari menggunakan font tipe sans serif menggunakan jenis font Fabrika, A Iternate Gothic2 BT, dan Ebrima.

\section{$\mathrm{Aa}$ Bb Cc Dd Ee Ff Gg Hh li Jj Kk LI Mm Nn Oo \\ Pp Qq Rr Ss Tt Uu Vv Ww Xx YyZz}

0123456789

Aa Bb Cc Dd Ee Ff Gg Hh li jj Kk LI Mm Nn Oo

Pp Qq Rr Ss Tt Uu Vv Ww Xx YyZz

0123456789

$\mathrm{Aa}$ Bb Cc Dd Ee Ff Gg Hh Ii Jj Kk LI Mm Nn Oo

Pp Qq Rr Ss Tt Uu Vv Ww Xx YyZz

0123456789

Gambar 2. JenisH uruf Terpilih

(Dok. Nur Hanifati Widyaningsih 2018)

\section{c) Warna}

Warna merupakan pelengkap gambar agar terkesan hidup.Warna juga merupakan unsur yang sangat tajam untuk menyentuh kepekaan sehingga dapat menimbulkan berbagai macam perasaan entah senang, sedih, terharu, dan sebaginya.A pabila pemakaian warna yang kurang tepat maka dapat merusak citra, mengurangi nilai keterbacaan, dan bahkan dapat menghilangkan gairah baca.Sehingga dalam perancangan A ugmented R eality berbasi android sebagai promosi Taman Sriwedari Surakarta ini harus mampu mencermikan suatu hal terkait Augmented Reality dan Taman Sriwedari Surakarta. Warna dasar dari desain Augmented Reality Sriwedari Surakarta setelah mengalami proses revisi untuk pergantian warna yang lebih melambangkan unsur teknologi dan budaya menggunakan warna biru, hitam, hijau, kuning dan putih.

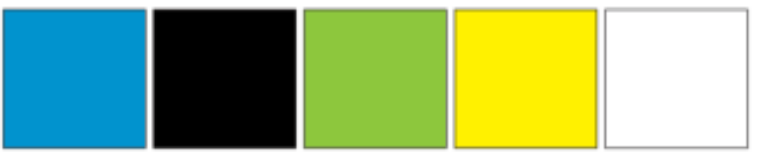

Gambar 3 Warna Terpiih

(Dok. Nur Hanifati Widyaningsih 2018) 


\section{d) Layout}

Pemilihan layout berdasarkan segmen yang dituju agar mau membaca serta tertarik terhadap kataloig ini.Layoutakan menggunakan tipe young and fun, dikarenakan segmen dari katalog ini yaitu anak muda, maka diperlukan tampilan lay out yang tidak lagi childish (kekanak-kanakan).

\section{Desain Logo A ugmented Reality Taman Sriweari Surakarta}

Perancangan logo dilakukan dari tahapan awal karena karya ini merupakan produk baru belum pernah ada yang membuat.Gapura Taman Sriwedari Surakarta yang melambangkan kebudayaan dan circuit untuk melambangkan teknoloogisebagai ide dari penciptaan logo dalam produk ini dengan konsep menggabungkan kebudayaan dengan teknologi. Logo untuk A ugmented Reality Taman Sriwedari Surakarta menggunakan logogram dan logotype akan digunakan dalam mendesain logo yang dimana simbol yang akan menampilkan identitas, karakter terkait Augmented Reality Taman Sriwedari Surakarta Berbasis android. Sesuai tema besar yang sebelumnya sudah ditentukan akan dijabarkan sesuai definisi sehingga menghasilkan sebuah logo yang memiliki konsep bentuk dari logogram yang akan digunakan sebagai logo aplikasi maupun untuk kepentingan foto profile identitas dan logotype tersebut digunakan untuk logo yang dapat mengenalkan produk dan aplikasi dari A ugmented Reality Taman Sriwedari Surakarta.
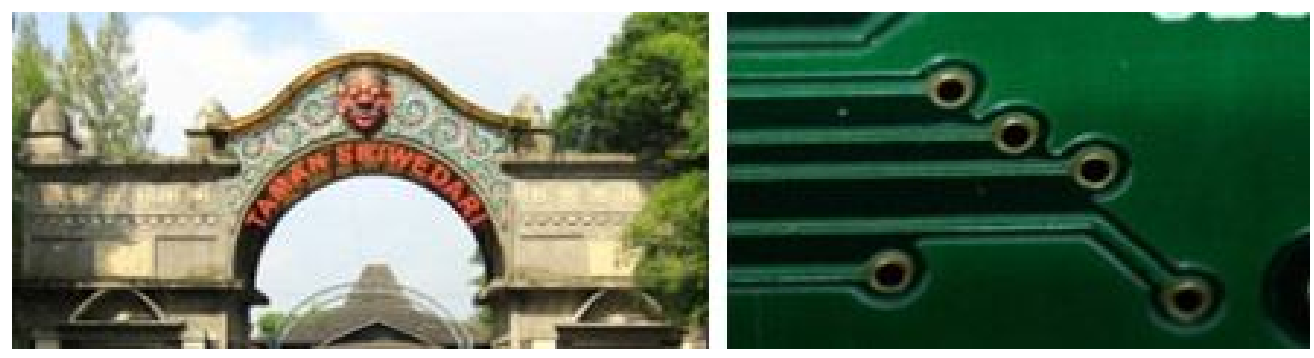

Gambar 4. Sumber Ide Logo

(Dok. Nur Hanifati Widyaningsih 2018)

\section{a. Proses B rainstorming Logo}

Proses perancangan sebuah identitas atau dikenal dalam istilah logo, memerlukan sebuah proses untuk menemukan sebuah temuan ide yang dapat mewakili produk yang ditawarkan. Hal tersebut dikenal dalam istilah Brainstorming. Brainstorming untuk A ugmented Reality Taman Sriwedari Surakarta sendiri ditempuh langkah-langkah seperti halnya mengumpulkan gagasan sebanyak mungkin sebagai upaya untuk memecahkan 
masalah dari mengkombinasikan unsur teknologi disini yaitu Augmented Reality dan android dengan unsur budaya diambil dari Taman Sriwedari Surakarta. Hasil brainstorming di atas, dapat dijelaskan dengan kata kunci antara lain:

1) Desain logo yang dihasilkan menggunakan kata kunci Taman Sriwedari dengan teknologi Augmented Reality.

2) Tema yang diambil dalam perancangan yaitu teknologi dan budaya.

3) Logo yang dibuat harus memiliki kesan yang simpel dan berkarakter.

4) Desain logo yang dirancang menggunakan logogram yang digunakan untuk logo aplikasi androiddan logotype digunakan untuk keperluan logo media cetak maupun digital selain foto profil kepentingan media sosial produk.

\section{b. Sketsa Kasar}

Hasil dari brainstorming di atas, maka dibuatlah sketsa kasar dalam membuat desain logo A ugmented Reality Taman Sriwedari.Sketsa ini dibuat dalam beberapa alternatif bentuk desain yang terkumpul. Gambar sketsa kasar nantinya akan dibuat digitalisasinya, berikut ini hasil dari proses penggambaran secara kasar menggunakan tangan diatas kertas yang didapat:

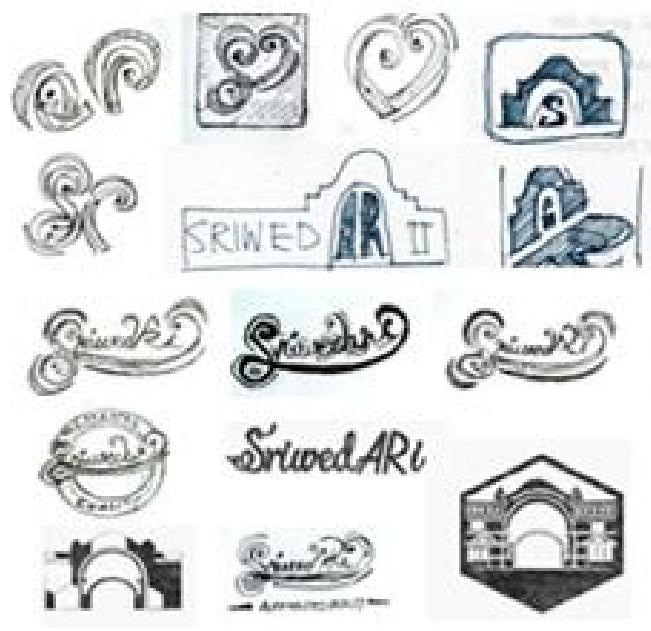

Gambar 5. Thumbnails Sketsa Kasar A Iternatif Logo

c. Digitaliasi

(Dok. Nur Hanifati Widyaningsih 2018)

Proses digitalisasinya untuk mendapatkan bentuk yang solid. Hasil dari proses thumbnail ini nantinya akan dipilih yang sesuai dengan karakter Augmented Reality Taman Sriwedari Surakarta. 


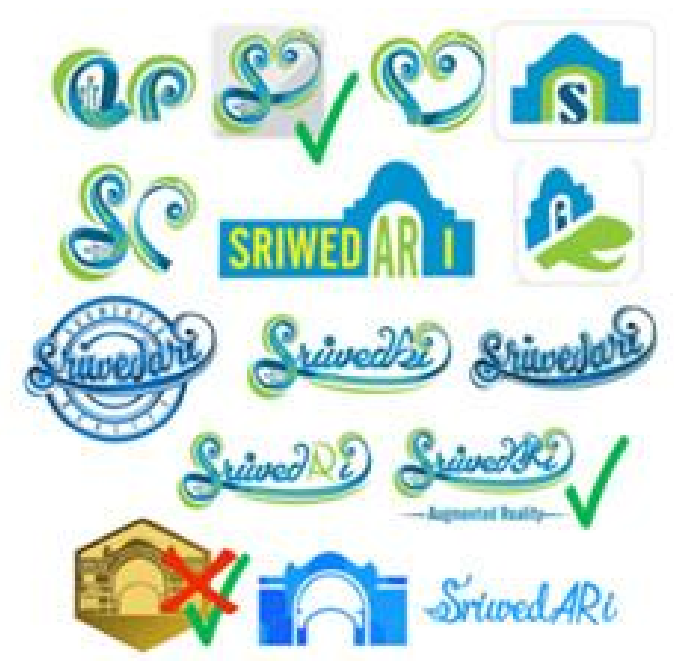

Gambar 6.Thumbnails Digitaliasi Alternatif Logo

(Dok. Nur Hanifati Widyaningsih 2018)

\section{1) Logotype}

Logotype pada gambar di atas merupakan logo hasil dari proses setelah revisi pada logo sebelumnya yang dianggap kurang masuk kedalam konsep perancangan, kemudian dibuatlah logo hasil dari revisian tersebut sesuai konsep yaitu menggabungkan unsur teknologi ( A ugmented Reality) dengan budaya ( Taman Sriwedari Surakarta ). Huruf pada logotype diatas terdapat tulisan kapital "AR" yang memiliki arti Augmented Reality.Ikon Sulur terdapat pada gapura Taman Sriwedari Surakarta yang dari zaman dahulu hingga sekarang belum pernah dirubah.Warna gelap dan terang menunjukan Kedalaman karena bidang garap 3D eksterior, garis lengkung dan lingkaran sebagai icon menunjukan kecanggihan teknologi.Logo ini digunakan untuk kepentingan brand merk pada media promosi digital maupun cetak.

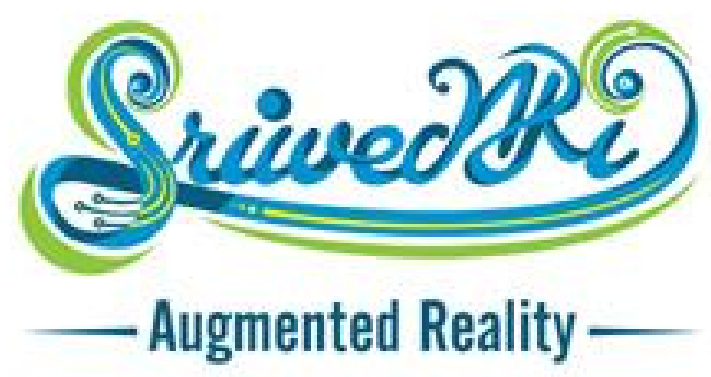

Gambar 7 Logotype Terpilih

(Dok. Nur Hanifati Widyaningsih 2018) 


\section{2) Logogram}

Logogram yang nantinya digunakan khusus sebagai ikon foto profil dari aplikasi SriwedARi untuk kepentingan media social, dan playstore.

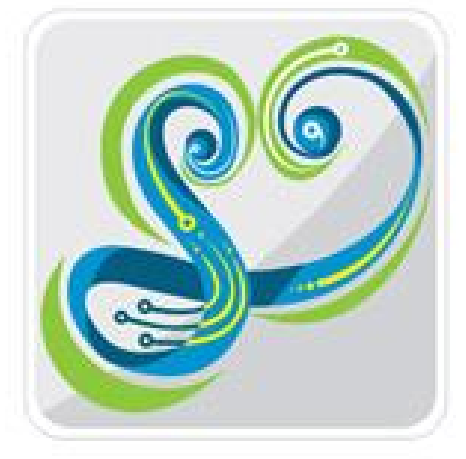

Gambar 8 Logogram Terpilih

(Dok. Nur Hanifati Widyaningsih 2018)

Logogram ini merupakan bentuk penyederhanaan dari logotype namun tidak meninggalkan unsure motif pada gapura Taman Sriwedari Surakarta dan unsure circuit, karena unsur tersebut sangat penting.Logogram ini memiliki makna saat pertama kali dilihat akan Nampak ikon hati yang memiliki arti mengajak mencintai warisan budaya. Logo ini juga melihatkan huruf "SR" berarti Sriwedari, jika logo diputar 300을 terbentuklah huruf "AR" memiliki arti A ugmented R eality, jika dikembalikan pada posisi semula setelah mengetahui artinya, maka akan terlihat huruf "S.A.R" yaitu Sriwedari A ugmented R eality.

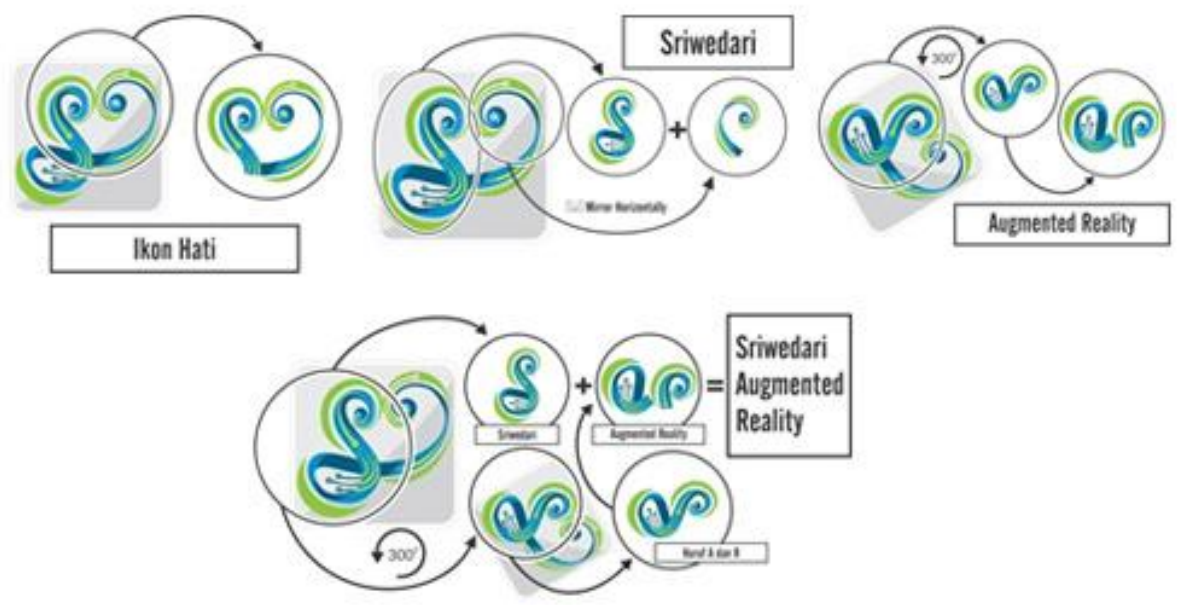

Gambar 9 Makna Logogram

(Dok. Nur Hanifati Widyaningsih 2018) 


\section{Pembuatan M arker Augmented Reality}

Desain marker final dari Augmented Reality Taman Sriwedari Surakarta. Desain tersebut tidak dilihat dari segi seni estetika desain komunikasi visual, namun gambar marker tersebut didadapatkan dari segi teknis supaya dapat digabungkan dengan A ugmented Reality, dinilai dari segi keterbacaan gambar marker pada program agar dapat terbaca lancar, pada akhirnya dilakukan usaha pemberian tanda ikon sarang lebah (segi enam) sebagai penanda urutan gambar, ikon tersebut didapatkan dari logo sebelum direvisi dan penambahan tipografi yang berbeda supaya marker tidak salah membaca gambar bangunan eksterior pada gambar yang akan dimunculkan nantinya.
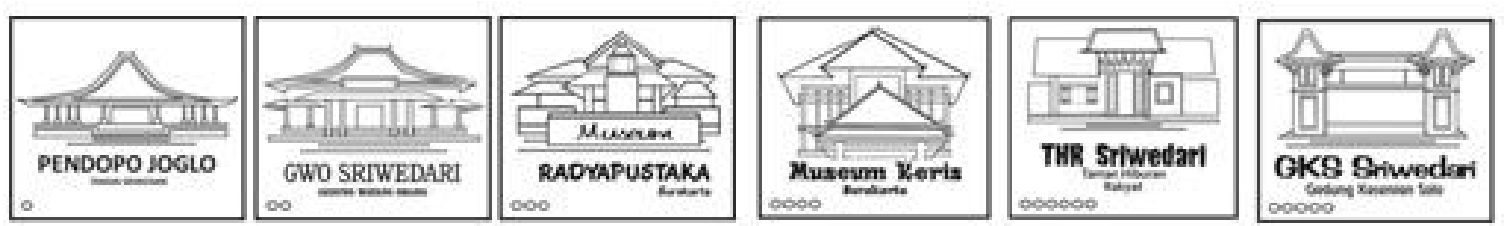

Gambar 10. M arker Terpilih

(Dok. Nur Hanifati Widyaningsih 2018)

\section{Desain Buku Katalog Taman Sriwedari Surakartaln Augmented Reality}

Desain buku katalog Taman Sriwedari Surakarta In A ugmented R eal ity menggunakan tipe layout young and fundengan warna-warna turunan yang berasal dari logo Sriwedari A ugmented Reality serta ilustrasi visual yaitu hasil 3D eksterior bangunan pada area taman tersebut. Buku katalog ini berisikan informasi mengenai Taman Sriwedari Surakarta, terdapat enam gambar marker beserta keterangan informasi mengenai bangunan tersebut, terdiri dari bangunan Pendopo Joglo, Gedung Wayang Orang, Museum Radya Pustaka, Museum Keris, Gedung Kesenian Solo, dan Taman Hiburan Rakyat Sriwedari nantinya dapat memunculkan bentuk 3D eksterior secara realtimedengan bantuan aplikasi bernama SriwedARi. 

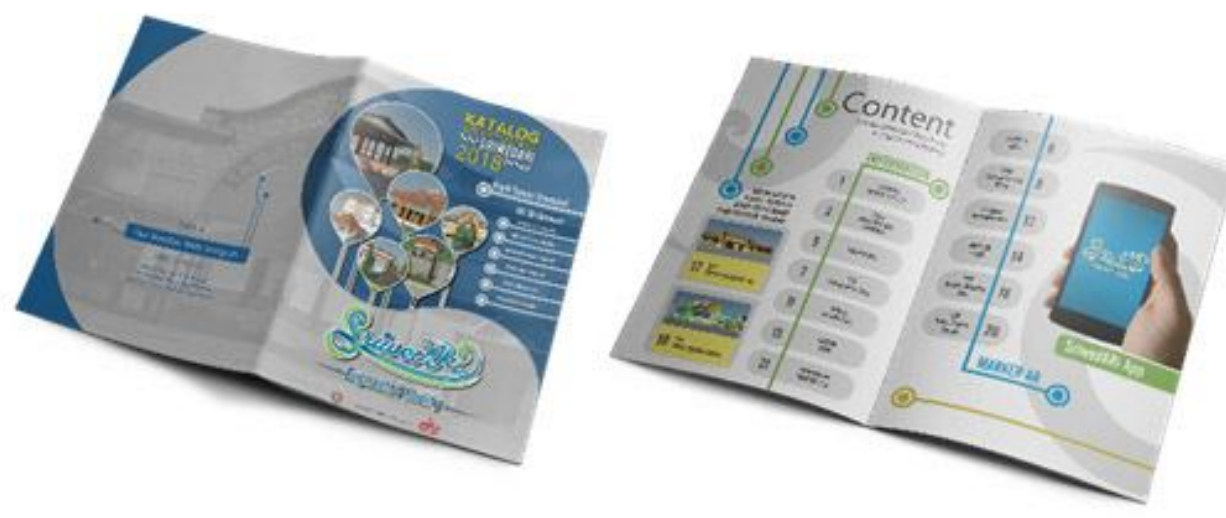

Gambar 11. Desain Buku Katalog Taman Sriwedari Surakarta In A ugmented R eality (Dok. Nur Hanifati Widyaningsih 2018)

\section{Pembuatan Video Sejarah Taman Sriwedari Surakarta}

Video ini dibuat animasi 2D dengan teknik typografi kinetic memiliki kemampuan story telling yang bagusmenceritakan tentang sejarah Taman Sriwedari Surakarta dari awal dibangun hingga masa sekarang dikemas dengan menarik disertai dengan musik latar belakang gending jawa.

\section{Pembuatan Desain 3D Eksterior}

Desain berupa 3D ( tiga dimensi) berisi eksterior bangunan Pendopo Joglo, Gedung Wayang Orang, Gedung Kesenian Solo, THR Sriwedari, Museum Keris, Musem Radyapustaka, serta bangunan 3D eksterior dari proyek revitaliasi pada tahun 2018 menggunakan software SketchU p 2016. Berikut ini tampian desainya

\section{Pembuatan Video Track View Revitalisasi 2018}

Video dari Revitalisasi Taman Sriwedari Surakarta pada tahun 2018 dibuat animasi 3D eksteriorbangunan menggunakan software Sketch Up, kemudian hasil dari 3D bangunan eksterior tersebuat dibuat track view menggambarkan bagian- bagian dari hasil revitalisasi nantinya, selanjutnya video ini dibuat menggunakan program A dobe After Effects CC untuk menambahkan efek suara dan tulisan. 


\section{Desain A plikasi}

Pembuatan desain user interface yaitu dapat membuat dan menampilkan interface dari aplikasi "SriwedARi" yang memiliki kesenadaan dalam hal warna, font, gambar, dan lain sebagainya, supaya dapat dengan mudah digunakan oleh target pengguna aplikasi ini nantinyaA plikasi pada saat proses login pertama akan menampilkan logo dari Sriwedari A ugmented Reality kemudian akan muncul main menu, aplikasi bernama "SriwedARi" berisi tombol button dari Video Sejarah Taman Sriwedari Surakarta, Start A R 3D Eksterior, H ow to Play, dan tombol Close.
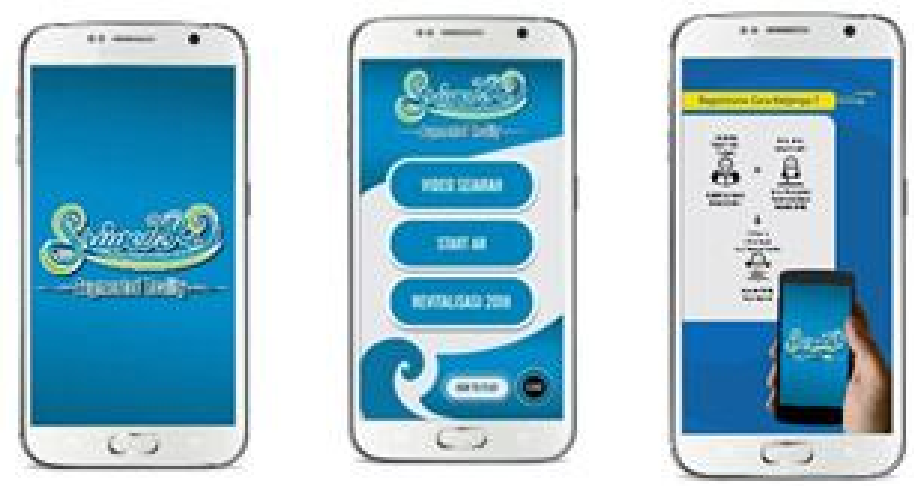

Gambar 15 Desain A plikasi

(Dok. Nur Hanifati Widyaningsih 2018)

\section{Buku dan A plikasi Augmented Reality Taman Sriwedari Surakarta}

Buku katalog Taman Sriwedari Surakarta In A ugmented Reality dan aplikasi bernama SriwedARi ini akan menjadi satu kesatuan produk yang tidak dapat dipisahkan agar dapat menghasilkan tampilan Augmented Reality Taman Sriwedari Surakarta berbasis android sesuai dengan konsepnya, karena tanpa aplikasi buku katalog ini akan terlihat seperti buku, sedangkan apabila digabungkan menggunakan apikasi buku ini menjadi unik yaitu dapat memunculkan gambar 3D eksterior dari bangunan yang terdapat pada taman tersebut dan juga dapat menikmati video sejarah dan revitalisasi tahun 2018. 


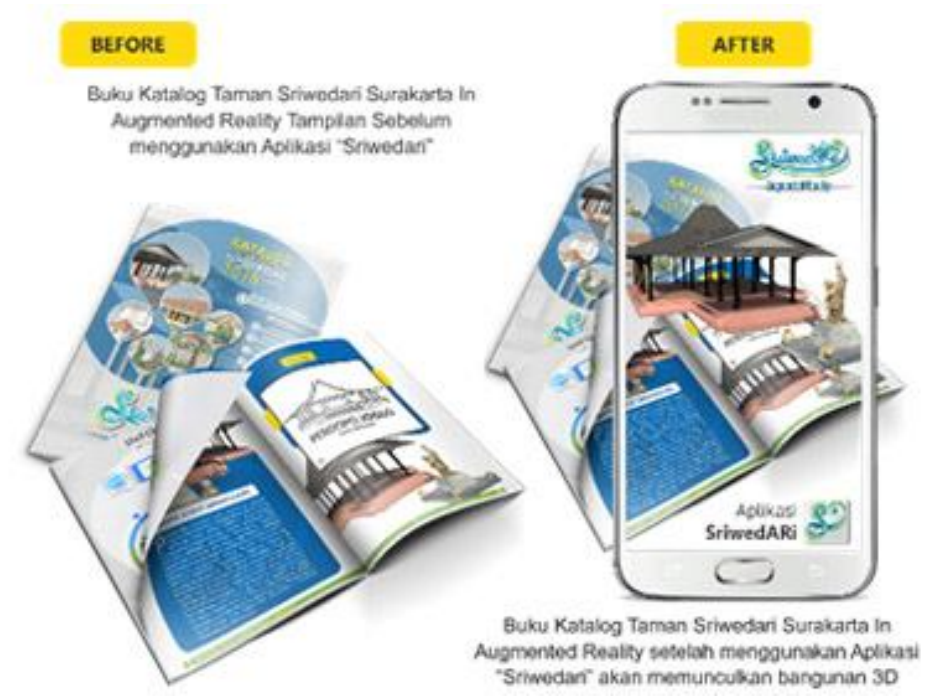

Gambar 16. Buku dan Aplikasi Augmented Reality Taman Sriwedari Surakarta (Dok. Nur Hanifati Widyaningsih 2018)

\section{Desain Promosi Lini A tas(Above The Line)}

Promosi dibutuhkan supaya buku katalog Taman Sriwedari Surakarta dan aplikasi "SriwedARi" supaya dapat dikenal oleh masyarakat khususnya anak muda, diperlukan kegiatan periklanan agar sampai kepada target konsumen. Media perikanan dibutuhkan baik media pendukung bersifat informasi maupun media pendukung yang bersifat mengingatkan, yang diantaranya, yaitu:

\section{a. Billboard}

Iklan berupa billbard pada Jalan A hmad Yani Surakarta yang berada pada area sekitar Terminal Tirtonadi ini memiliki eye catching yang maksimal karena efek lampu merah dan efek posisi jalan meengkung serta berada pada perempatan. Lokasi hanya berjarak sekitar 200 meter dari pusat perdagangan Nusukan dan satu meter dari pusat Grosir Pasar Legi serta merupakan jalur lalu lintas yang selalu padat, dekat dengan pusat transformasi dan atau terminal sekaligus jalur antar propinsi.

\section{b. Media Massa}

Media massa berupa Koran Solopos ini tepat untuk memuat iklan visual dari katalog Taman Sriwedari Surakarta serta aplikasi "SriwedARi". Koran ini tidak hanya dibeli secara pribadi, rumah tangga, maupun perusahan. Koran ini nantinya diletakan pada ruang tunggu sebagai fasilitas agar dapat dibaca dan dapat ditemukan di perpustakaan. 
eISSN 0000-0000

p-ISSN 0000-0000

Vol. 00, A pril 2020

Media ini sangat efektif dan fleksibel untuk marketing communication, selain itu koran juga merupakan media iklan dengan tarif lumayan terangkau.

\section{Desain Promosi Lini Bawah(Below The Line)}

Program promosi penting dilakukan untuk memperkenalkan kepada publik. Pemilihan sasaran promosi tidak boleh dilakukan dengan sembarangan atau tidak terkonsep dnegan baik dengan melihat situasi yang sedang berkembang yang didasarkan atas analisis menyeluruh situasi pasar saat ini (Handriyotopo, 2004). Demikian pula strategi promosi yang dilakukan untuk mempromosikan SriwedariARi.

Media promosi lini bawah (below the line) memilih menggunakanpersonal selling dengan media pembatas buku, stiker, gantungan kunci, dan pin. Media cetak pada poster dan x stand banner.Media promosi menggunakan media sosial instagramdan facebook, sedangkan untuk promsi aplikasi dengan playstore.Media untuk mempermudah konsumen mendapatkan buku katalog dengan toko online.

\section{a. Personal Selling}

1) Pembatas Buku

Pembatas buku dipilih agar dapat digunakan sebagai pembatas dan simbol identitas yang dapat mengingatkan kepada Taman Sriwedari Surakarta in A ugmented Reality.

2) Stiker

Sticker dipilih media pendukung promosi yang bisa ditempelkan pada benda padat sebagai pengingat.

3) Gantungan Kunci dan Pin

Gantungan kunci dan pindipilih media pendukung promosi yang bisa dipasang pada benda padat sebagai pengingat.

\section{b. Media Cetak}

1) Poster

Print A dvertising yaitu berupa poster merupakan salah satu media yang akan menjadi sarana promosi untuk memperkenalakan adanya katalog Taman Sriwedari Surakarta dan aplikasi "SriwedARi"

2) X Stand Banner

Media standing banner berfungsi sama seperti poster namun penempatan dari media ini akan diletakkan pada tempat-tempat yang berhubungan dengan anak muda dan 
dapat juga digunakan sebagai display untuk menunjang promosi katalog Taman Sriwedari Surakarta maupun aplikasi SriwedARi .Media ini sangat singkat dan jelas terlihat dengan diletakan di tempat stategis yaitu pada Terminal Tirtonadi dan Stasiun Solo Balapan untuk menarik perhatian calon konsumen.

\section{c. Media Sosial}

1) Instagram

Instagram dipilih karena merupakan aplikasi sosial media yang memiliki potensial cukup besar sebagai pendukung promosi dari katalog Taman Sriwedari Surakarta dan aplikasi AR Sriwedari.Aplikasi instagram ini memiliki banyak peminat dan diketahui sekarang penggunanya telah mencapai lebih dari satu milyar.

2) Facebook

Facebook dipilih karena telah menjadi media sosial paling popular di Negara Indonesia. Merupakan situs jejaring sosial berbasis web, namun seiring perkembangan teknologi dan banyak penggunanya. Penggunaan facebook sebagai media pendukung promosi dari katalog Taman Sriwedari Surakarta dan aplikasi AR Sriwedari ini mimiliki potensial yang cukup besar.

\section{d. Playstore}

A plikasi bernama Sriwedari nantinya akan di u ploud pada media playstoreagar para calon konsumen dapat dengan mudah melakukan proses mengunduh program ini lalu menginstal pada smartphone android mereka masing-masing secara personal.

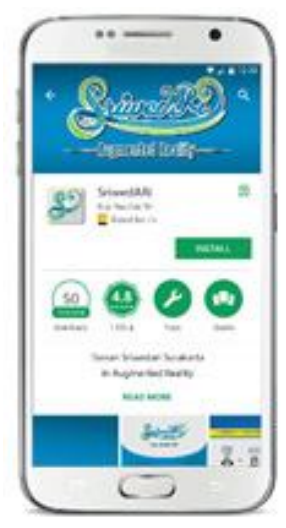

Gambar 26Iklan Pada Playstore (Dok. Nur Hanifati Widyaningsih 2018)

\section{e. Media Toko 0 nline}

Kegunaan iklan pada media toko online yaitu memudahkan calon pembeli untuk mendapatkan buku katalog Taman Sriwedari Surkarta in Augmented Reality.Versi cetak dari 
eISSN 0000-0000

p-ISSN 0000-0000

Vol. 00, A pril 2020

buku katalog ini nantinya akan tersedia pada toko on line seperti Shopee, Buka Lapak, dan Tokopedia.

\section{KESIMPULAN}

Perancangan buku katalog Taman Sriwedari Surakarta in Augmented Reality dan aplikasi bernama "SriwedARi" adalah jawaban yang tepat dalam upaya melestarikan serta mengenalkan harta artefak warisan budaya kepada anak muda dengan menanfaatkan teknologi A ugmented Reality berbasis Android. Perancangan A ugmented Reality menjadi lebih atraktif, menarik, dan mendidik serta sebagai sarana pelestarian Taman Sriwedari Surakarta sebagai cagar budaya. Teknis analisis difusi inovasi melalui metode M ultimedia D evelopment Live Cycle, layout design, penggunaan tipografi dan warna yang memiliki nilai estetik yang terinspirasi dari gapura yang dipadukan dengan rekaya teknologi. Konsep perancangan ini menghasilkan identitas visual SriwedARi, buku katalog yang berisikan marker dan informasi, serta aplikasi bernama SriwedARi. Strategi promosi periklanan sebagai upaya memperkenalkan produk ini menggunakan media above and below the line juga melalui toko online.

Teknogi AR dapat diadopsi dalam jenis dan obyek material lain dalam menghadapi destrubtion teknologi dimana manusia dimudahkan untuk dapat mengetahui tentang sesuatu seperti museum dan artefak budaya secara digital merupakan sebuah peradaban baru manusia dalam memperoleh informasi selain media sosial via internet.

\section{DAFTAR PUSTAKA}

Ardika , I Wayan. 2007. Pustaka Bu daya dan Pariwisata. Denpasar: Pustaka Larasan.

Handriyotopo. 2004. Peranan Perancang Komunikasi V isual.Jurnal OrnamenVol.1 N o.1. Januari. Penerbit: ISI Surakarta Pres

IDC (International Data Corporation). 2016. Smartphone O S M arket Share, Q32016yang diakses melalui http:/ / www.idc.com/ prodserv/ smartphone-os-market-share.jsp yang diakses pada 5 Mei 2017 pukul 06.00.

Pasca Sarjana Universitas Negeri Malang. 2016. PR O SID IN G :Inovasi Pendidikan di Era Big D ata dan Aspek Psikologinya. Malang : Program Studi Teknologi Pembelajaran dan Psikologi Pendidikan Pasca Sarjana Universitas N egeri Malang.

Sutopo, Aresto Hadi. 2013. Teknologi Informasi dan Komunikasi Dalam Pendidikan.Yogyakarta : Graha Ilmu. 